REVUE DE L'INSTITUT

FRANÇAIS D'HISTOIRE

EN ALLEMAGNE

\section{Revue de l'IFHA}

Revue de l'Institut français d'histoire en Allemagne

$1 \mid 2009$

IFHA 1

\title{
Textes et Identités au haut Moyen Âge
}

Atelier international de doctorants, Auxerre, 17-19 octobre 2008

\section{Laurent Jégou}

\section{OpenEdition}

\section{Journals}

Édition électronique

URL : https://journals.openedition.org/ifha/318

DOI : $10.4000 /$ ifha.318

ISSN : 2198-8943

Éditeur

IFRA - Institut franco-allemand (sciences historiques et sociales)

\section{Édition imprimée}

Date de publication : 30 septembre 2009

Pagination : 37-39

ISSN : 2190-0078

Référence électronique

Laurent Jégou, "Textes et Identités au haut Moyen Âge », Revue de l'IFHA [En ligne], 1 | 2009, mis en ligne le 07 février 2013, consulté le 28 juin 2022. URL : http://journals.openedition.org/ifha/318 ; DOI https://doi.org/10.4000/ifha.318

Ce document a été généré automatiquement le 29 septembre 2020

(CIFHA 


\section{Textes et Identités au haut Moyen Âge}

Atelier international de doctorants, Auxerre, 17-19 octobre 2008

Laurent Jégou

\section{NOTE DE L'ÉDITEUR}

Rapport établi par Laurent Jégou

1 Le groupe de recherches doctorales Texts and Identities in the early Middle Ages s'est réuni, les 17, 18 et 19 octobre 2008 au Centre d'Études Médiévales d'Auxerre (France), à l'occasion de cet atelier, organisé par les universités de Cambridge, Vienne, Leeds, Utrecht, Paris I et Paris Ouest-Nanterre ainsi que par l'Institut für Mittelalterforschung de Vienne et la Mission Historique Française en Allemagne.

Régine Le Jan (Université Paris I Panthéon-Sorbonne) ouvrit la session en rappelant les motivations qui ont poussé les «mères et pères fondateurs" du programme, les professeurs Rosamond McKitterick (Cambridge), Mayke de Jong (Utrecht), Ian Wood (Leeds) et Walter Pohl (Vienne) à mettre sur pied ces colloques annuels. Ce groupe s'est élargi en 2003 aux doctorants de R. Le Jan et, cette année, à ceux de François Bougard (Université Paris Ouest). L'intention était de proposer à leurs étudiants respectifs de donner régulièrement un état de l'avancement de leurs travaux, de confronter leur recherche à celle d'autres doctorants et de prendre connaissance des orientations méthodologiques que prend la médiévistique dans les différents pays concernés. Cette expérience internationale leur permet également de bénéficier des remarques d'intervenants à la table ronde qui suit chaque intervention. En l'occurrence, participaient à cette table ronde Dominique Iogna-Prat (CNRS-LAMOP), Sylvie Joye (Reims), Marcelo Candido da Silva (Sao Paulo), Laurent Jégou (Université Paris I) et Irene van Renswoude (Utrecht). Deux orientations majeures guident les communications du programme Texts and Identities: la transmission des textes et leur tradition manuscrite d'une part, la perception des différences sociales, politiques et 
religieuses qui transparaît dans les textes altimédiévaux d'autre part. Les textes servent alors de stratégies de distinction à ceux qui les composent, les utilisent, les compilent...

3 Ces trois journées ont permis d'entendre 21 communications, réparties thématiquement en six sessions. La première porta sur la place de l'écrit dans les conflits. Les textes médiévaux sont composés et exploités comme un instrument d'affirmation des prétentions des différents protagonistes : c'est le cas par exemple des adversaires de Clotaire II, qui forgèrent les preuves destinées à prouver la bâtardise de ce dernier. De même, l'évêque Rathier a composé des œuvres propres à soutenir sa lutte contre les revendications des chanoines de Vérone. Les communications de la deuxième session furent consacrées à la représentation du pouvoir à travers des sources aussi diverses que les actes conciliaires, les lois barbares, les textes hagiographiques ou les règles monastiques. Les participants à la troisième session analysèrent la manière dont les textes permettent de définir les communautés, que celles-ci soient familiales ou spirituelles, ces dernières étant mieux connues grâce à la lexicographie menée sur un corpus de textes narratifs ou exégétiques, ou qu'elles soient façonnées par des motivations politiques (autour de Théodulfe d'Orléans).

Les textes ont également soutenu des revendications matérielles et spirituelles, lorsque les clercs ont composé, compilé et forgé des œuvres hagiographiques propres à défendre les prétentions de leur saint patron sur un territoire : ce fut l'objet de la quatrième session. Il apparaît ainsi que le pontifical de Sens, qui contient l'un des plus anciens ordines de consécration royale, a lui aussi été composé dans l'objectif de soutenir les prétentions des souverains non-carolingiens, tous consacrés par l'archevêque de Sens au début du Xe siècle. Les communications regroupées dans la cinquième session portèrent sur le public visé par la production écrite. L'œuvre exégétique composée par un Raban Maur a eu de multiples usages, comme la méditation, l'enseignement ou la prédication. De même, les Cambridge songs, singulier florilège composé à la fin du Xe siècle, mêlent latin et vernaculaire, textes littéraires et burlesques, pour un public qui semble avoir été très large. Enfin, la session finale aborda une thématique qui a occupé une place de choix lors des premières réunions de Texts and Identities : l'ethnicité et l'altérité telle qu'elle est présentée dans les textes, et la place de l'écrit dans la définition de cette identité. L'identité propre à l'Église bretonne (ou anglaise) est démontrée à travers l'analyse du culte de saint Alban, qui remet en cause l'idée d'une rupture totale entre le paysage religieux de l'Antiquité tardive et l'organisation d'une Église bretonne attribuée à Augustin de Canterbury. D'autre part, les œuvres littéraires donnent l'occasion d'appréhender l'altérité, à travers l'image des Vikings dans l'œuvre d'Hincmar, et celle des Romains dans l'Historia romana de Paul Diacre.

5 La participation financière apportée par la Mission Historique Française en Allemagne (Göttingen), le Centre d'Études Médiévales (Auxerre), l'École Doctorale de l'université Paris I Panthéon-Sorbonne, les universités de Cambridge, Vienne, Leeds, Utrecht, Limoges et Paris Ouest-Nanterre a concouru au succès de cette rencontre, qui s'est déroulée dans des conditions matérielles exceptionnelles.

Ont participé à cet atelier : Shane Bobrycki, Tom Faulkner, Sally Lamb, Richard Pollard (Cambridge), Erin Dailey, Michael Garcia, Mark Tizzoni (Leeds), Jens Schneider (Limoges), Gaëlle Calvet-Marcadé, Laurence Leleu, Claire Tignolet (Paris I PanthéonSorbonne), Émilie Kurdziel, Valentina Toneatto (Paris Ouest-Nanterre), Erik Goosmann, 
Rutger Kramer, Annika Rulkens (Utrecht-Amsterdam), Nicola Edelmann, Gerda Heydemann, Maya Maskarinec, Marianne Pollheimer, Veronika Wieser (Vienne). 